\title{
Application of explosives in the oil industry
}

\author{
Erick Galante $^{1}$, Assed Haddad ${ }^{2}$, Nathália Marques ${ }^{3}$ \\ ${ }^{1}$ Instituto Militar de Engenharia, IME, Rio de Janeiro, Brazil \\ ${ }^{2}$ Universidade federal do Rio de Janeiro, UFRJ, Rio de Janeiro, Brazil \\ ${ }^{3}$ BW OffShore, Rio de Janeiro, Brazil
}

Email address:

egalante@ime.eb.br(E. Galante), assed@poli.ufrj.br(A.Haddad), nathalia.marques@bwoffshore.com(N. Marques)

\section{To cite this article:}

Erick Galante, Assed Haddad, Nathália Marques, Application of Explosives in the Oil Industry. International Journal of Oil, Gas and Coal Engineering. Vol. 1, No. 2, 2013, pp. 16-22. doi: 10.11648/j.ogce.20130102.11

\begin{abstract}
The 20th century was largely dependent upon fossil fuel, in particular petroleum. The petroleum industry provides fuel and other compounds for modern society, ranging from natural gas, passing through diesel and culminating with polymers. These polymers are seeing in every aspect of modern life (books, computers, cars, foams, cloves, and so on). Due to this dependency, modern society would collapse without petroleum derivatives. The main source for raw petroleum rests in the deep sea, where the oil is imbedded in the rocks under the sea. The location of petroleum reservoirs and implementing the extraction facility requires large amounts of explosives. Due to the complexity of the subject, this paper presents the set of explosive applications in the oil industry, discussing applications and which explosives are used in each and every one of these applications. The main contribution of this paper is to provide easiness on finding general information regarding explosives in the oil industry, as well as provide solid ground and background information for other studies.
\end{abstract}

Keywords: Explosives, Oil Industry, Perforation Charges, Review

\section{Introduction}

The petroleum industry provides fuel and other compounds for modern society. These petroleum derivatives are mainly distilled from raw petroleum, which is obtained from sedimentary rocks. In Brazil, for example, the main source for raw petroleum rests in the deep sea, where the oil is imbedded in the rocks under the sea. The location of petroleum reservoirs and implementing the extraction facility requires large amounts of explosives. Explosives are used, for example, to generate a shockwave under the soil, which helps mapping the underground (using radar / sonar technology). Explosives are also applied in order to assure smooth drilling the soil, allowing easier and faster access to the oil reservoirs. Despite other applications, one can state that "Perforating charges" are the most important use of explosives in the entire oil extraction business. There "Perforating charges" are the explosives charges used to start the oil flow when all the hardware is set in place and ready to operate, by perforating the concrete and metal tubes installed in the well. These charges rely upon Monroe effects of the shape charges to perforate the hardware with minimal structure damage/compromise.

\section{Objectives}

This paper presents and consolidates the set of explosive applications in the oil industry, discussing applications and which explosives are used in each and every one of these applications.

\section{Explosives Overview}

There are many definitions for explosives [1], [2], [3], [4], [5], [6]; however, they all share the same core definition. To quote just one important source, Rudolf Meyer [4] defines explosives as solid or liquid substances, alone or mixed with one another, which are in a metastable state and are capable, for this reason, of undergoing a rapid chemical reaction without the participation of external reactants such as atmospheric oxygen. The reaction can be initiated by mechanical means (impact, Impact Sensitivity; friction, Friction Sensitivity), by the action of heat (sparks, open flame, red-hot or white-hot objects), or by detonating shock (Blasting Cap with or without a W Booster charge).

The definition provided by [4] is very complete one, from which it is possible to understand an explosive as a kind of combustible material, which is capable of undertaking a 
combustion reaction at very high reaction rates, rates of such magnitude that becomes a detonation.

However, regarding to its products, the detonation products may differ from those from combustion, due to side-reactions that might come into existence driven by the high pressure and temperature of the detonation.

Some relevant properties and characteristics of explosives are presented throughout this paper.

\section{The Oil Industry}

The [7] provides a figure of the size and potentials of this industry: until December 2009 it was recorded in the world a total of 913,978 producing oil wells, with a world production of 70,908,600 (approximately 71 million) barrels of oil per day. According to the same source, in 2009 only Brazil had a total production of 1,950,000 (two million) barrels of oil per day.

Within this context, one can understand that the industrial oil is a strategic sector of great importance. At the same time, this sector suffers from huge levels of complexity, which is remarked by new technological requirements. These requirements are inherent in oil exploration and production in conditions never before imagined and increasingly waters deep.

From the Analyses of the Database Exploration and Production (BDEP) of a Brazilian Oil Agency (ANP)[8], one gets an overview of oil and natural gas existing in Brazil, realizing the growth potential of this industry in the coming years. These growing potential relates to deep-sea exploration.

Deep-sea potentials are concentrated in larger quantities and volume in the states of Rio de Janeiro, Sao Paulo and Espirito Santo.

It is also important to address the environmental issues within the oil industry. The impacts to the environment, however, are not limited only to the pollution caused by oil spills, but mainly for the production and use of energy as a whole. According to La Rovere, the relationship between energy and the environment is very intense due to the use of natural resources and the environmental impacts involved along the chain of production, processing, transportation, distribution, storage and end-use energy. It is founded that on each link in this chain there are a number of potential risk factors to cause damage to human health and the environment.

\section{Results and Discussion}

Explosives are chemical compounds capable to undertake a rapid decomposition, which generates gases and energy at high rates. These outputs in such rates (above sound velocity) can be converted in significant amount of work (thermodynamic work). This work can be used in some ways within the oil industry, mainly in seismography and in perforation.

\subsection{Exploration - Seismographic Charges}

Before the probes, sonar and radars became common in the oil industry, explosives were largely used in seismography.

The method consisted in use the explosive to create a shockwave within the soil, which would propagate and generate echoes. These echoes could be measured in sonars placed on ground level. Then, specialist would build an approximated map of the underground from the information collected by the sonar. These maps could be used to guide the drilling operations [9], [10], [11].

Under this background, one can design the explosive requirements and setup. An overview can be seen in Fig 1.

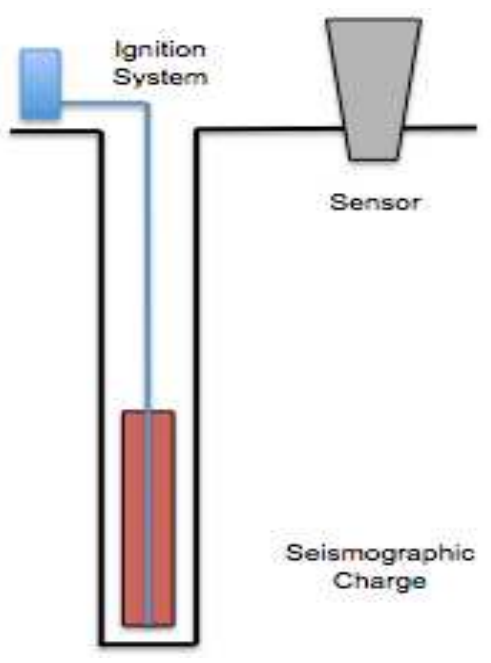

Figure 1. Seismographic charge setup

Every explosive has two main characteristics when it comes to output: Brisance and Force. Brisance relates to the shockwave and, therefore, to the velocity of detonation of the explosive. On the other hand, Force relates to the increment in pressure, provided by the rate in which gaseous products are created.

Furthermore, since the seismographic operation requires shockwave propagation and not an increase in pressure, the explosive used should move towards a high detonation velocity possible at the same time as keeping the pressure at a minimum.

To achieve a minimum pressure, two aspects of the chemical composition should be dealt with: heat temperature and moles of gaseous produced per mass of explosive. From the second (ration between gaseous moles in the products and explosive mass), all nitro amine based explosives are cut of from the list. Therefore, high explosives like hexogen $(\mathrm{RDX})[12],[13],[14],[15]$, [16] and Octogen (HMX) are NOT to be considered [1], [2].

Further analyzing the key feature of the interest in the shockwave not in the force, the explosive engineer would not consider the use of explosive emulsions, since they detonate at velocities around $3000-4000 \mathrm{~m} / \mathrm{s}$, relatively low when comparing to RDX and HMX (around $8.000 \mathrm{~m} / \mathrm{s}$ ). At the same time, explosive emulsions favor force due to its 
chemical composition (oxidizer agent diluted in water, hydro-carbon based fuel, emulsion agent and other additives).

From this point, the explosive engineer would narrow the choices to commercially available explosives with the desired characteristics. The most likely explosive to be chosen would be the Pentaerythrol tetranitrate (PETN). PETN is relatively easy to manufactory and largely used as explosive core in the mining industry. According to [4]; PETN has a detonation velocity of $8.400 \mathrm{~m} / \mathrm{s}$ and a heat of explosion of $1408 \mathrm{kCal} / \mathrm{kg}$. Both within the requirements force the energy output into a shockwave and less into pressure. It is important to remark that there will always be shockwave and force in any high explosive. The aim of the explosive engineer in this application is assure that more energy will be converted in shockwave than in pressure.

However, PETN is not cast able in any safe procedure, since its melting point $\left(141,3^{\circ} \mathrm{C}\right)$ is close to its deflagration temperature $\left(190^{\circ} \mathrm{C}\right)[4]$. Hence, a binding agent is required.

The selection of binding agent should take into account the energy output and the reaction products. This is to keep the maximum energy possible converted in a shockwave. To keep the energy output at optimum levels, this binding agent should be energetic, in other words, this binding agent should burn exothermically. Within the military applications, the TNT is largely used as an energetic binding agent. It is due to TNT melting point being measured at temperatures below those of boiling water $\left(100^{\circ} \mathrm{C}\right)$.

From this point, the explosives are selected (PETN and TNT). The next stage is defining the proportions. The more PETN the best, however each binding agent has an adsorption capability, above with the explosive will not hold mechanical integrity and properties. From experiments, one can determine that the TNT cannot hold more than $70 \%$ of PETN. This figure, however, is not practicable within the industry, since the TNT-PETN mixture would become far too thick and viscous.

Some explosive manufacturer [17] developed a seismographic charge containing 55\% PETN and $45 \%$ TNT. This composition is most likely derived from its filling capabilities. This seismographic charge is still available in the Brazilian marketing. Its seismographic charges are shown in figure 2 .

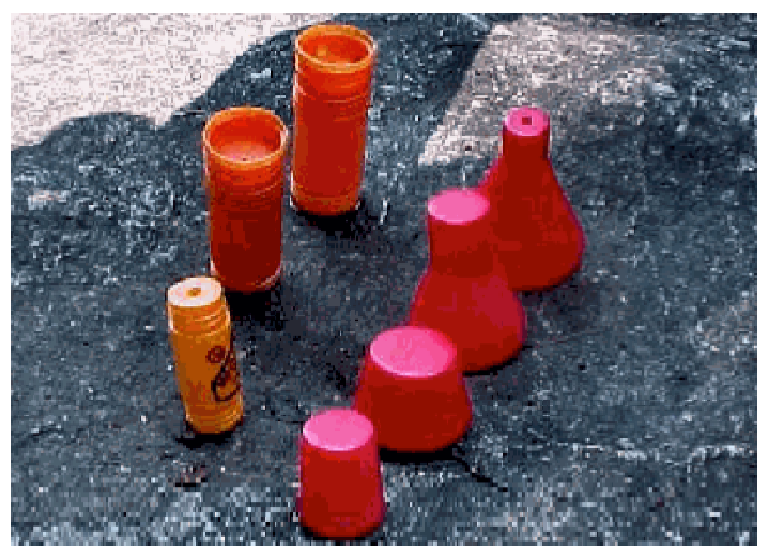

Figure 2. Seismographic charge - Example

\subsection{Drilling and Perforation}

With exploration in harsh environments and consequent high pressure and temperature conditions, the calculation of reservoir properties has become complex and thus the changes in pressure transient response need to be understood and appreciated by taking appropriate challenging measures, impacting the technique used for drilling and perforating the reservoir. [18], [19], [20], [21].

This section of the paper presents discusses and analyses explosives applications (mainly perforation charges) in drilling and perforation.

\subsubsection{Drilling}

The drilling technology was developed to increase the drilling efficiency based on 3 basic reasons, i.e.: safety, minimum cost, and usable hole. Casing drilling is one of drilling technology which it has been applied in many oil fields in Indonesia. [22], [23]

The casing drilling is classified into 3 methods, i.e.: Retractable Bit, Liner Drilling, and Drilling with Casing, where each method can be applied in certain condition. Recently, the drilling technology has reached efficiency significantly, both in engineering and economical aspects, especially in the formation which is difficult to drill with conventional drilling method [22], [23].

Generally, the drilling efficiency can be formulated based on statistic trend from the field data. Thus, the application of seismographic charges in mapping the reservoir allows a more accurate drilling and a more efficient field.

Many methods were developed in drilling operations as an effort to increase the efficiency of drilling operation, thus it can be reached less time, minimum cost, and the best result. [22], [23]. Most of the drilling methods apply explosives in a way similar to a mining operation or a starting a outdoor mine, with controlled explosions to increase the efficiency in work the soil.

Therefore, drilling does not present any particular requirement for the explosive to fulfil, except those already discussed for the seismograph charges.

\subsection{Perforation Charges}

This section of the paper presents discusses perforation charges. Perforation charges are those explosives devices used to facilitate drilling the wheels.

\subsubsection{Framework of Perforation Charges Application}

The use of perforation charges relates to the drilling techniques currently available, as well as to the methods used to build the wells. Furthermore, the techniques and methods applied in the oil wells and drilling relates to the geologic characteristics of the reservoir [24], [25], [26], [27], [28].

The oil reservoirs are not a homogeneous and continuous pool of oil. In fact the reservoirs are the collection of oil spread within sedimentary rocks. One can proper figure an oil reservoir from Fig 3 

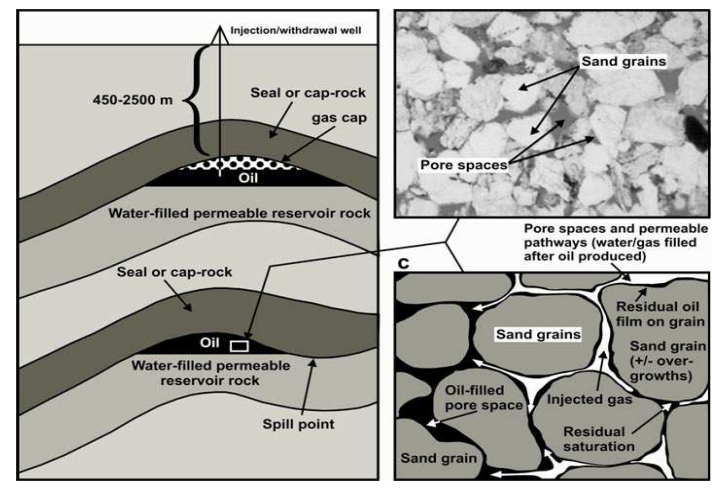

Figure 3. Schematics of an Oil Reservoir [29]

Due to the nature of the reservoir, the drilling operation occurs at the same time as the construction of the pipelines[30]. These pipelines are an annulus of concrete around the drilling equipment, put in place to assure the reservoir does not suffer effects from the pressure gradient create by the drilling (i.e. the centre of the annulus) [24], [25], [26], [27], [28].

The perforation charges are used to drill holes in the wall of the concrete annulus (roughly $90^{\circ}$ from the drilling axis), allowing pressure difference between the oil and the pipelines, density differences between oil and water and equipment installed to pump the oil to the surface.

\subsubsection{Perforation Charges Application}

The perforation charges are assembled in large equipment, also known as cannon. The cannon are mainly a metallic structure in which the charges are assembled, as well as the igniting explosive setup. The Fig 4 present a schematic image of such setup [31].

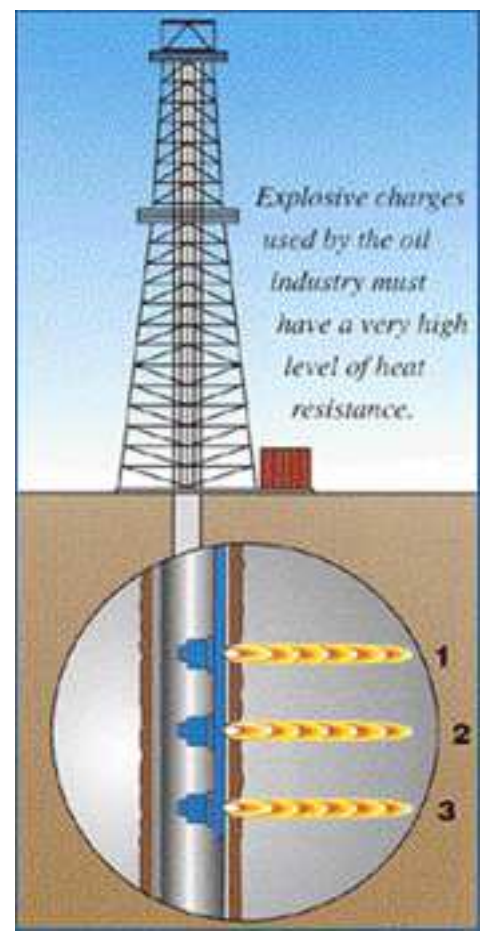

Figure 4. Schematics of a canon and perforation charges in place [31]
Upon firing, it is expected that the entire set of perforation charges ignite and drill holes in the concrete. In order to achieve the length in the concretes, the perforation charges rely upon the shape charge concept. Fig 5 present a schematic image of the firing mechanism [31].

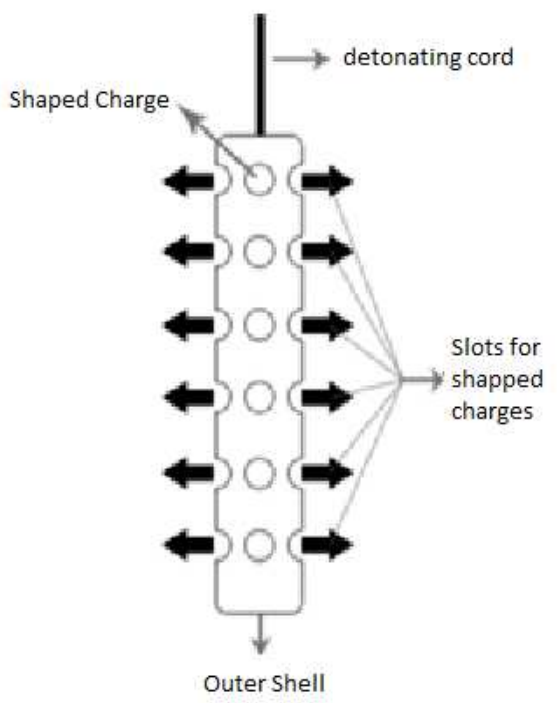

Figure 5. Schematics of a canon and perforation charges [32]

\subsubsection{Perforation Charges as Shape Charges}

A shaped charge is an explosive charge that benefits from the Munroe effect to maximize its penetration and perforation capabilities [1], [2], [4], [33], [34], [35], [36].

The Munroe effect relies upon the "V" shape of the explosive free surface. Since the shockwave tends to resemble the explosive surface on its neighborhoods, the "V" allows a resultant force to be formed. This force is represented by a vector $\mathbf{v}$ in the axis of the image of Fig 6.

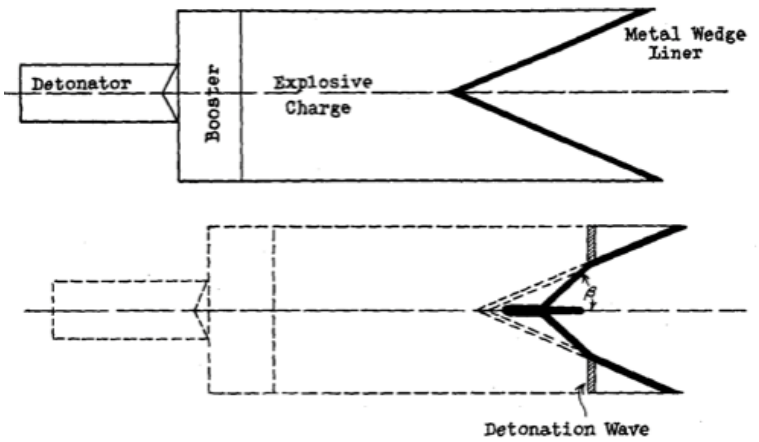

Figure 6. Shaped Charge resultant force [33]

The major part of the shockwave's energy is directed according to the vector $\mathrm{v}$, increasing the forces in the direction of the vertices of the "V" shape.

However, this concentration of energy is not enough nor is the best use of the Munroe effect. The ultimate penetration capability is achieved throughout the use of a liner on top of the explosive (Fig 7). More often, the liner is made of metal. 


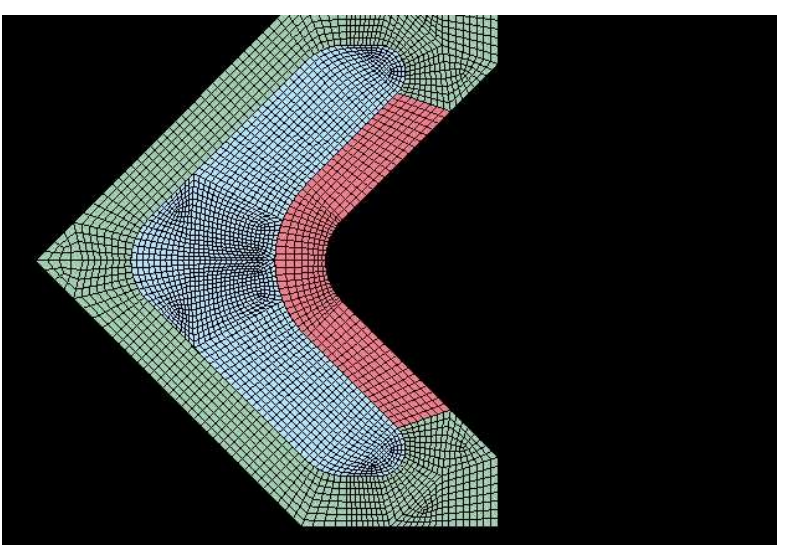

Figure 7. Shape charge and liner

During the explosion, the forces and pressures in place achieve very high values and the liner is squeezed out, forming a metal jet. This happens due to the force in place surpasses the Young's modulus, forcing the liner to undergo a plastic deformation and behavior like a fluid and move along with the shockwave (i.e. vector v). The Fig 8 presents a metal liner been squeezed out of the shaped charge device

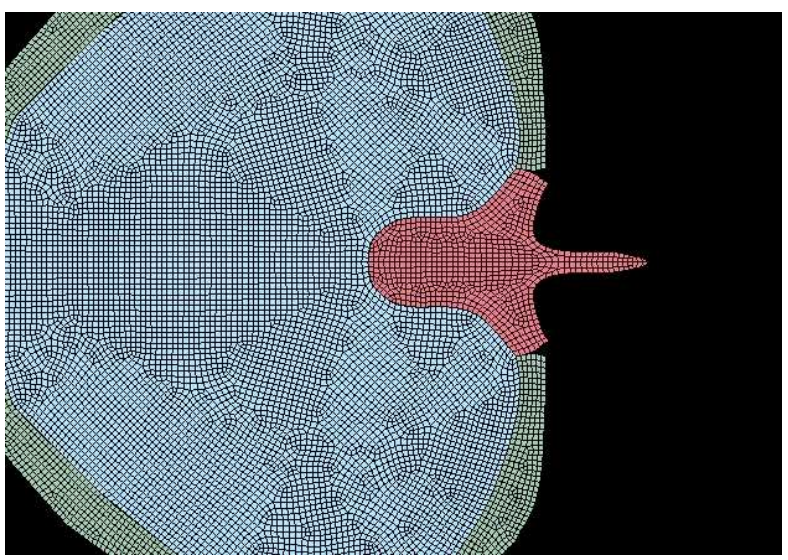

Figure 8. Liner been squeezed out the Shape charge

Therefore, it is important to design and performance to match the output energy of the explosive and mechanical characteristics of the liner.

One way of estimate of the penetration length is comparing a shaped charge jet with a hydrodynamic penetration. As studied by [35] and[36] the penetration is proportional to the length of the penetrator, the square root of the density of the penetrator, and inversely proportional to the square root of the density of the target. It is usual to add an efficiency factor $\eta$ in the equation to allow for the fact that penetration is not purely hydrodynamic and materials properties have a small effect, so that the final result is the equation (1). The Eq (1) allows one to relate jet length $(l)$, viscosity $(\eta)$ and densities (target $\left(\rho_{\mathrm{t}}\right)$ and metal liner $\left.\left(\rho_{\mathrm{y}}\right)\right)$ with performance (depth of penetration).

$$
p=\operatorname{lin} \sqrt{\frac{p_{y}}{p_{r}}}
$$

Another key feature for long depth penetration is the solid angle of the "V" shape. For wider "V" angle (closer to $180^{\circ}$ ) the jet formed would resemble less like an arrow and more like a shaft, reducing penetration depth. For closer angles (closer to $0^{\circ}$ ), there would be far too much energy and mass in a very narrow space, disturbing the jet formation. Many references [1], [2], [4], [34], [35], [36] present $43^{\circ}$ as the optimum number for the " $\mathrm{V}$ " angle.

\subsubsection{Explosive Requirements}

From the characteristics of the perforation charge, one explosive engineer can draw the main characteristics regarding performance of the explosive charge: high energy output.

For an explosive, energy output translates into velocity of detonation and charge density. Keeping the velocity of detonation as a key parameter, a large number of high explosives could fulfil the task. As for the density, the charge could be pressed (instead of casted), which would increase the density.

However these are not the only boundary conditions for the explosive design. The explosive should be able to safely get deep into the well and remain there until detonation is required. These aspects of the application narrow the list of suitable explosives.

This occurs due to the environmental in which the explosive will be exposed and used at. In deep-sea oil extraction operations, for example, the explosive would be taken more than 300 meters below sea level. In these depths the pressure is 300 times higher than at sea level. This increases the forces over the explosive, which may lead to an unexpected detonation.

To avoid this safety issue, it is likely to use more stable and pure explosives. The table 1 presents some safety characteristics of commonly used military high explosives.

Table 1. High explosives characteristics 错误! 未找到引用源。

\begin{tabular}{lllll}
\hline Characteristic & TNT & RDX & PETN & HMX \\
\hline Density, crystal $(\mathrm{g} / \mathrm{cm} 3)$ & 1.654 & -- & 1.76 & $1.96^{(1)}$ \\
Detonation velocity $(\mathrm{m} / \mathrm{s})$ & 6.900 & 8750 & 8.400 & 9.100 \\
Melting point $\left({ }^{\circ} \mathrm{C}\right)$ & 80.6 & 204 & 141.3 & 282 \\
Heat of Explosion $(\mathrm{kCal} / \mathrm{kg})$ & 1.210 & 1.439 & 1.408 & 1.435 \\
\hline
\end{tabular}

${ }^{(1)}$ Beta-Crystalization

Analyzing the figures from table 1, from the safety aspect, an explosive engineer would favor a nitro amine based explosive, such as RDX or HMX.

Comparing the safety aspects with performance, both RDX and HMX are suitable choices, varying upon manufacturer.

It is important to remark that in order to ignite the perforation charges it is required a set of other explosive acces- 
sories to the task. These accessories would be blasting caps, detonation cords, and shock tube, among others.

Since these accessories would also be operating at the same hostile environment as the perforation charge, they would require RDX or HMX as a payload.

\subsection{Well stimulation Techniques}

Stimulation is required in many oil and gas wells to achieve economic rates of production. Low production rates can be due to formation damage from drilling or completion fluids, inadequate perforation penetration, relatively low permeability formations or lack of connection to natural fracture networks. Traditional methods of stimulation include well shooting with explosives, hydraulic fracturing and the injection of fluids such as acids, solvents or de-emulsifiers [37].

Some of these techniques, such as Controlled Pulse Fracturing (CPF) [37] use explosives .The CPF process uses an electrically ignited tool containing a solid propellant charge placed in the wellbore adjacent the zone requiring placed in the wellbore adjacent the zone requiring stimulation.

Recently, Controlled Pulse Fracturing (CPF), also known as Tailored Pulse Fracturing or High Energy Gas Fracturing, has been developed to alleviate some of the above problems or make traditional methods more effective. A typical commercial CPF stimulation involves the use of a wireline run, electrically ignited propellant which is placed across the formation to create a high pressure pulse.

Regarding the explosive charges, they are propellant charges operating under relatively standard environmental conditions; therefore there is not a further requirement for stability and reliability. Furthermore, since the charge ignites in an adjacent setup, a miss fire would not open the wheel.

\section{Conclusion}

One can conclude that the applications of explosives within the oil industry are significant and fundamental in the current technological stage of exploration. It is also possible to conclude that not any explosive can be used, due to the hostile environmental in place at deep-sea operations, been RDX and HMX the more suitable choices.

\section{References}

[1] J. Akhavan, The Chemistry of Explosives, Third Edit. Norfolk: Biddles Ltd., Kings Lynn, Norfolk, 2011.

[2] P. Cooper, Explosives Engineering. Wiley-VCH, Inc. United States of America, 1996.

[3] K. Kuo, Principles of combustion, 2nd ed. John Wiley \& Sons, 2005.

[4] R. Meyer, J. Köhler, and A. Homburg, Explosives, 6th, Compl. Weinheim: Wiley-VCH Verlag GmbH, Weinheim, 2007.
[5] department of Defense, Risk-Based Explosives Safety Analysis, no. 14. Alexandria, Virginia: Explosives Safety Board, 2000.

[6] J.-C. Martin, Incendies et Explosions D'Atmosphère, Première. Presses Polytechniques et Universitaires romandes, 2008, p. 574.

[7] H. PennWell, "OIL \& GAS JOURNAL," Worldwide look at reserves and production, 2010. [Online]. Available: http://www.ogj.com. [Accessed: 01-Feb-2010].

[8] ANP, "Year book for statistics regarding Petroil and Gas production in Brazil - Anuário Estatístico Brasileiro Do Petróleo, Gás Natural E Biocombustíveis," Rio de Janeiro, Brazil, 2011.

[9] M. Khandelwal and T. N. Singh, "Prediction of blast-induced ground vibration using artificial neural network," International Journal of Rock Mechanics and Mining Sciences, vol. 46, no. 7, pp. 1214-1222, Oct. 2009.

[10] M. Khandelwal and T. N. Singh, "Evaluation of blast-induced ground vibration predictors," Soil Dynamics and Earthquake Engineering, vol. 27, no. 2, pp. 116-125, Feb. 2007.

[11] M. Khandelwal and T. N. Singh, "Prediction of blast induced ground vibrations and frequency in opencast mine: A neural network approach," Journal of Sound and Vibration, vol. 289, no. 4-5, pp. 711-725, Feb. 2006.

[12] W. J. Lukasavage and N. Slagg, "Process for preparation of RDX," Patent number US5250687, International Classification: C07D251061993.

[13] J. A. Meredith, "Preparation of RDX," Patent number US3937703. International Classification C07D25154.1976.

[14] C. P. Achuthan and G. Mullick, "HAZARDS IN THE MANUFACTURE OF RDX AND HMX," Defence Science Journal, vol. 33, no. 1, pp. 91-95, 1983.

[15] W. E. Bachmann and J. C. Sheehan, "A new method of preparing the high explosive RDX," Journal of the American Chemical Society, vol. 71, no. 5, pp. 1842-1845, 1949.

[16] J. T. Leach and J. M. Staples, "Hazards of inadvertent mixing of chemicals used in the Bachmann processes for manufacturing the military explosives RDX and HMX," Journal of Hazardous Materials, vol. 4, no. 3, pp. 271-281, Jan. 1981.

[17] IMBEL, "IMBEL," 2013. [Online]. Available: www.imbel.gov.br. [Accessed: 17-Jul-2013].

[18] P. Shah, H. Pandya, H. Sharma, and A. Saxena, "Offshore Drilling \& Well Testing of a HPHT Gas Well: A Case Study," in Proceedings of SPE Oil and Gas India Conference and Exhibition, 2012.

[19] J. Panjwani, N. Kothari, S. Pooniwala, and M. Mahajan, "Application of Sand Jet Perforations for Multizone Fracturing in CBM Wells, India," in Proceedings of 2013 SPE/ICoTA Coiled Tubing \& Well Intervention Conference \& Exhibition, 2013.

[20] K. K. Millheim, "Advances in Drilling Technology and Where Drilling Technology Is Heading," in Proceedings of International Meeting on Petroleum Engineering, 1986.

[21] W. Davila, A. Azizov, G. Han, and E. Magnuson, "Practical 
Directional Drilling Techniques and MWD Technology in Bakken and Upper Three Forks Formations in Williston Basin North Dakota to Improve Efficiency of Drilling and Well Productivity," in Proceedings of 2013 SPE Middle East Unconventional Gas Conference \& Exhibition, 2013.

[22] J. Hasling, "Impacts of Technology on Communicating Weather Windows for Offshore Construction, Drilling and Intervention Operations," in Proceedings of 2013 Offshore Technology Conference, 2013.

[23] A. Buntoro, "Casing Drilling Technology as the Alternative of Drilling Efficiency," in Proceedings of IADC/SPE Asia Pacific Drilling Technology Conference and Exhibition, 2008.

[24] H. Williams, L. Anbao, F. Zhang, P. Jianxin, C. Baumann, Y. Xiangtong, and K. Barnard, "Prediction and Reduction of Perforating Gunshock Loads," in Proceedings of 6th International Petroleum Technology Conference, 2013.

[25] C. Baumann, E. Pesantes, J. Guerra, A. William, and H. Williams, "Reduction of Perforating Gunshock Loads," SPE Drilling \& Completion, vol. 27, no. 1, Mar. 2012.

[26] C. Baumann, M. Benavides, A. Martin, A. Salsman, and H. Williams, "Perforating on Wireline - Weak-Point Load Prediction," in Proceedings of SPE/EAGE European Unconventional Resources Conference and Exhibition, 2012.

[27] P. Valdivia, H. Williams, P. Stecchini, A. Pando, and C. Baumann, "Perforating Gunshock Loads - Prediction and Mitigation," in Proceedings of 2013 SPE / IADC Drilling Conference and Exhibition, 2013.

[28] D. Atwood, W. Yang, B. Grove, and L. Behrmann, "Flow Performance of Perforation Tunnels Created With Shaped Charges Using Reactive Liner Technology," in Proceedings of 8th European Formation Damage Conference, 2009.
[29] British Geological Survey, "British Geological Survey," 2013, 2013. [Online]. Available: http://www.bgs.ac.uk/research/energy/undergroundGasStora ge.html. [Accessed: 17-Jul-2013].

[30] K. Dey and V. M. S. R. Murthy, "Prediction of blast-induced overbreak from uncontrolled burn-cut blasting in tunnels driven through medium rock class," Tunnelling and Underground Space Technology, vol. 28, pp. 49-56, Mar. 2012.

[31] France, "Eurenco Group," 2013. [Online]. Available: http://www.eurenco.com/en/explosives/high_explosives.htm 1. [Accessed: 17-Jul-2013].

[32] Vieira, "Perforation Charges in Petroil - CANHONEIO EM POÇOS PETROLÍFEROS," 2011.

[33] G. Birkhoff, D. P. MacDougall, E. M. Pugh, and S. G. Taylor, "Explosives with Lined Cavities," Journal of Applied Physics, vol. 19, no. 6, p. 563, 1948.

[34] F. Yang, C. Li, S. Cheng, L. Wang, and W. Tian, "Deformation behavior of explosive detonation in electroformed nickel liner of shaped charge with nano-sized grains," Transactions of Nonferrous Metals Society of China, vol. 20, no. 8, pp. 1397-1402, Aug. 2010.

[35] R. M. Lloyd, Conventional Warhead Systems Physics and Engineering Designs. Universidade de Michigan: Progress in Astronautics and Aeronautics, 1998, p. 636.

[36] W. P. Walters and J. A. Zukas, Fundamentals of shaped charges, 1st ed. Universidade de Michigan: Wiley-VCH, Inc. United States of America, 1989, p. 398.

[37] H. W.C. and W. R. Shu, "Controlled Pulse Fracturing for Well Stimulation," in Proceedings of Low Permeability Reservoirs Symposium, 1989. 